\title{
EVALUACIÓN DE LA FERTILIDAD in vitro DEL SEMEN DE TOROS JÓ- VENES NACIONALES EN OVOCITOS PROVENIENTES DE OVARIOS DE ANIMALES BENEFICIADOS
}

\author{
Evaluation of In Vitro Fertility of Semen from Young Local Bulls in \\ Oocytes from Ovaries of Slaughtered Animals
}

\author{
Próspero Cabrera V. ${ }^{1,2}$, Washington Yoong K. ${ }^{1}$ y Gicell Gamarra L. ${ }^{3}$
}

\section{Resumen}

\begin{abstract}
El presente trabajo se desarrolló en el Centro de Investigación y Enseñanza en Transferencia de Embriones (CIETE), convenio Universidad Nacional Agraria La Molina (UNALM) - Ministerio de Agricultura (MINAG); ubicado en el campus de la Universidad Nacional Agraria La Molina. El objetivo fue evaluar la fertilidad y la producción de embriones in vitro de cuatro toros provenientes del Banco Nacional de Semen. Se utilizaron 1031 ovocitos de calidad A y B aspirados de ovarios de vacas beneficiadas en el camal. Los ovocitos se maduraron en medio TCM-199. En la separación espermática se usó el método de centrifugación con gradientes de Percoll; la capacitación y fertilización se realizó en el medio TALP-IVF + PHE; y el cultivo de embriones se hizo con medio Sofaa + $5 \%$ de Suero Fetal Bovino (SFB). Los embriones fueron evaluados los días 7, 8 y 9 después de la fertilización. No se encontraron diferencias estadísticas entre los cuatro toros evaluados, siendo el porcentaje de fertilización de $63.3,56.8,68.8$ y 72.9\% para cada toro. Tampoco se encontró diferencias estadísticas en la producción de embriones entre toros. Se concluye que los toros evaluados se encuentran en el rango normal de producción de embriones in vitro.
\end{abstract}

Palabras clave: ovocito, embriones, blastocistos, Percoll

\section{Abstract}

This study was carried out in the Center of Research and Instruction in Embryo Transfer (CIETE), sponsored by a partnership between the National Agrarian University of La Molina (UNALM) and the Ministry of Agriculture (MINAG), located at the UNALM campus. The objective was to evaluate the fertility andin vitro production of embryos of four bulls from the National Semen Bank. This study used 1031 oocytes of quality A and B obtained from ovaries of the local slaughterhouse. The oocytes were matured in the TCM-199 medium. The Percoll gradient centrifuge method was used for spermatic separation; sperm capacitation and fertilization was done in the TALP-IVF + PHE medium; and embryos were cultured with the Sofaa medium containing 5\% Fetal Bovine Serum

\footnotetext{
${ }^{1}$ Departamento de Producción Animal, Universidad Nacional Agraria La Molina, Lima

${ }^{2}$ E-mail: procecavi@lamolina.edu.pe

${ }^{3}$ Investigador del Centro de Investigación y Enseñanza en Transferencia de Embriones (CIETE), Lima
} 
(FBS). Embryos were evaluated on days 7, 8, and 9 after fertilization. There were no statistical differences among the four bulls, and the fertilization rate was 63.3, 56.8, 68.8 and $72.9 \%$ for each bull. There was no statistical difference in the production of embryos between bulls. It is concluded that the bulls tested were in the normal range for in vitro embryo production.

Key words: oocytes, embryo, blastocyst, Percoll

\section{INTRODUCCIÓN}

La fertilización in vitro (IVF) ofrece nuevas dimensiones en la reproducción animal. Esta técnica consiste, básicamente, en la exposición de ovocitos maduros a espermatozoides capacitados, de tal manera que se produzca la fecundación fuera del oviducto materno. El éxito del procedimiento se demuestra al producir individuos vivos procedentes de IVF, utilizando tanto ovocitos madurados in vivo o madurados in vitro, aunque la eficiencia de estos procesos es inferior a la fecundación natural (Lorenzo et al., 1994). Esta técnica tiene una ventaja adicional en la producción de animales F1 en zonas con climas adversos (Olivera, 2003).

Cada laboratorio establece un tipo de clasificación para los ovocitos recuperados que se van a someter a procedimientos in vitro. Los ovocitos pueden ser clasificados de acuerdo al número de capas de células del cumulus y la apariencia del citoplasma (Ramírez y Jiménez, 1993). Las células del cumulus son subpoblaciones de células de la granulosa que proveen de nutrientes al ovocito y sintetizan la matriz compuesta de ácido hialurónico y proteínas que juegan un papel importante en el transporte del ovocito a través del oviducto y que permite atrapar al espermatozoide para la fertilización (Arlotto et al., 1996).

El número de espermatozoides que se emplea en IVF es aquel que produce la máxima fertilización con el mínimo de polispermia (Salgado et al., 2005). Por otro lado, Palma et al. (2001) señalan que 20 a $40 \%$ de los ovocitos seleccionados para maduración in vitro alcanzan el estadio de blastocisto; sin embargo, existe una amplia variabilidad en las tasas de desarrollo por efecto del toro.

En el presente estudio se tuvo como objetivo la evaluación de la fertilidad in vitro de cuatro toros jóvenes del Banco Nacional de Semen con ovocitos provenientes de ovarios de camal, especialmente referido a las tasas de fertilización de ovocitos, al porcentaje de embriones viables y al desarrollo embrionario.

\section{Materiales Y Métodos}

\section{Lugar de Trabajo}

La investigación se desarrolló en el Centro de Investigación y Enseñanza en Transferencia de Embriones (CIETE), convenio de la Universidad Nacional Agraria La Molina (UNALM) con el Ministerio de Agricultura (MINAG), Lima.

Los ovocitos se obtuvieron de ovarios de animales faenados en el camal de Yerbateros, Lima. Así mismo, se utilizó el semen de cuatro toros jóvenes del Banco Nacional de Semen (tres repeticiones por toro).

\section{Producción de Embriones In Vitro}

Se preparó una solución fisiológica con $5 \mathrm{ml}$ de estreptomicina en baño maría a 35 ${ }^{\circ} \mathrm{C}$, que se llevó en un termo al camal para el traslado de los ovarios al laboratorio. Los ovocitos se aspiraron en un ambiente aséptico con jeringas de $5 \mathrm{ml}$ y aguja $\mathrm{N}^{\circ} 20$, y se colocaron en placas petri de $100 \mathrm{~mm}$. Para- 
este fin, se utilizó el medio de aspiración MDPBS. Los ovocitos se ubicaron con un estereoscopio a 20x y se les clasificó en clase A, B, C y D, según el número de capas de células del cumulus que cubrían al ovocito (Ramírez y Jiménez, 1993), utilizándose para la presente investigación solamente los de calidad A y B. Los ovocitos fueron llevados a la cabina de flujo laminar, y colocados en gotas de $200 \mu \mathrm{l}$ con medio de maduración IVM en placas de $60 \mathrm{~mm}$, cubiertas con $8 \mathrm{ml}$ de aceite mineral. Las placas se colocaron en una incubadora de $\mathrm{CO}_{2}$ al $5 \%$ y $38.5^{\circ} \mathrm{C}$ por 22-24 horas.

Luego del periodo de incubación, los ovocitos madurados se transfirieron al medio de fertilización in vitro Talp-IVF. Para esto, los ovocitos se lavaron con el medio de fertilización y se colocaron en las placas de IVF, almacenándose en la incubadora de $\mathrm{CO}_{2}$ hasta el momento de la inseminación.

Para la capacitación espermática se utilizó el método de gradientes de Percoll al 90 y $45 \%$. El semen fue descongelado en agua a $35^{\circ} \mathrm{C}$ por $30 \mathrm{~s}$; se le añadió lentamente en la gradiente de Percoll y se centrifugó a 4000 rpm. Se retiró el sobrenadante y se agregó $200 \mu \mathrm{l}$ de Talp-IVF, se evaluó la motilidad post capacitación espermática y se contó el número de espermatozoides en la cámara de Neubauer. El semen se guardó en la incubadora a $38{ }^{\circ} \mathrm{C}$ hasta el momento de la inseminación, en que se utilizó una concentración de $1 \times 10^{9}$ de espermatozoides/ml.

Al día siguiente de la inseminación (Día 1) se prepararon las placas del medio de cultivo temprano SOFaa más 5\% de suero fetal bovino (SFB). Se retiraron las placas de IVF de la incubadora de $\mathrm{CO}_{2}$ y los ovocitos fertilizados se lavaron con SOFaa dentro de la cabina de flujo laminar. Los ovocitos parcialmente desnudados se colocaron en las placas de SOFaa y se guardaron en la incubadora de $\mathrm{CO}_{2}$. Luego de dos días (Día 3), se preparó un tubo de SOFaa con 5\% de SFB que se colocó en la incubadora de $\mathrm{CO}_{2}$ por 2 horas para hacer el cambio del medio de cultivo. Para esto, se retiraron las placas de SOFaa de la incubadora, renovándose la gota de SOFaa retirando $75 \mu 1$ dos veces y reemplazándolo con el nuevo medio con las mismas cantidades. Hecho esto, se volvió a llevar la placa de SOFaa a la incubadora de $\mathrm{CO}_{2}$.

El tercer cambio de SOFaa (Día 6) se realizó igual que el procedimiento del día 3, pero además, se evaluaron los embriones, anotándose las divisiones embrionarias y estadios de los embriones a fin de identificar aquellos que llegaron a desarrollar al día 7 .

En el día 7 se retiraron las placas de SOFaa, tomándose en cuenta solamente los embriones en estadio de mórula compacta, blastocisto temprano, blastocisto y blastocisto expandido. Estos embriones fueron posteriormente evaluados los días 8 y 9.

\section{Análisis Estadístico}

Los resultados se expresaron en porcentaje de fertilidad de los toros y porcentaje de blastocistos viables al día 7, 8 y 9 postinseminación. En el análisis estadístico se utilizó el diseño completamente al azar. Las diferencias entre tratamientos se evaluaron por la prueba de Duncan, empleando el comando LSMEANS del programa SAS (Statistical Analysis System).

\section{Resultados y Discusión}

No se encontró diferencias estadísticas entre toros con relación al porcentaje de fertilidad in vitro de los ovocitos (Cuadro 1). Los porcentajes de fertilidad para cada toro se encuentran entre 56.8 y $72.9 \%$, similar a lo obtenido por Salgado et al. (2005) (68\% de fertilidad y $12 \%$ de polispermia utilizando un millón de espermatozoides), Bastidas et al. (1999), Ratto (1999) y Galli (2003). 
Cuadro 1. Ovocitos provenientes de animales beneficiados que fueron fertilizados in vitro y blastocistos obtenidos mediante el empleo de semen de toros jóvenes procedentes del Banco Nacional de Semen

\begin{tabular}{lcccc}
\hline & Toro 1 & Toro 2 & Toro 3 & Toro 4 \\
\hline $\mathrm{N}^{\circ}$ de ovocitos & 270 & 280 & 186 & 295 \\
$\mathrm{~N}^{\circ}$ de ovocitos fertilizados & 171 & 159 & 128 & 215 \\
$\mathrm{~N}^{\circ}$ de blastocistos & 55 & 56 & 60 & 88 \\
$\%$ Fertilización & $63.3^{\mathrm{a}}$ & $56.8^{\mathrm{a}}$ & $68.8^{\mathrm{a}}$ & $72.9^{\mathrm{a}}$ \\
$\%$ Blastocistos $/ \mathrm{N}^{\circ}$ de ovocitos & $20.34^{\mathrm{a}}$ & $20.0^{\mathrm{a}}$ & $32.3^{\mathrm{a}}$ & $29.8^{\mathrm{a}}$ \\
$\%$ Blastocistos $/ \mathrm{N}^{\circ}$ de ovocitos & $33.2^{\mathrm{a}}$ & $35.2^{\mathrm{a}}$ & $46.9^{\mathrm{a}}$ & $40.9^{\mathrm{a}}$ \\
\hline fertilizados & & & & \\
\hline
\end{tabular}

${ }^{a, b}$ Valores dentro de filas con superíndices diferentes son estadísticamente significativos $(p<0.05)$

Cuadro 2. Porcentaje de motilidad postdescongelación y postcapacitación con Percoll en semen de toros jóvenes procedentes del Banco Nacional de Semen

\begin{tabular}{lcccc}
\hline & Toro 1 & Toro 2 & Toro 3 & Toro 4 \\
\hline $\begin{array}{l}\text { \% Motilidad } \\
\text { postdescongelación }\end{array}$ & $55.0 \pm 13.2$ & $65.0 \pm 8.7$ & $53.3 \pm 11.5$ & $56.7 \pm 5.8$ \\
$\begin{array}{l}\text { \% Motilidad } \\
\text { postcapacitación con Percoll }\end{array}$ & $56.7 \pm 5.8$ & $73.3 \pm 11.5$ & $66.7 \pm 5.8$ & $61.7 \pm 2.9$ \\
\hline
\end{tabular}

El porcentaje de blastocitos obtenidos en relación al total de ovocitos y con el número de ovocitos fertilizados fue ligeramente superior en dos toros, aunque sin haber diferencias estadísticas (Cuadro 1). Madrid (2003), evaluando toros con diferentes tasas de no retorno (alta, media y baja), tampoco encontró diferencias entre toros en la producción de blastocistos y en el desarrollo de los embriones, pero los porcentajes de fertilidad y de producción de blastocistos fueron mayores. No obstante, otros autores reportan valores similares a los del presente estudio (Alberio, 2003; Galli, 2003). Asimismo, la tasa de desarrollo de blastocistos en base al total de ovocitos madurados y al de ovocitos fertilizados fue similar a los resultados encontrados por Palma (2001), lo cual indica que en la última década, de un 20 a $40 \%$ de los ovocitos seleccionados para maduración in vitro alcanzan estadios de blastocistos.

Se encontró una gran variabilidad dentro de toros con relación a la obtención de blastocistos. Es así, que en el Toro 1 se obtuvo entre 15.0 a $25.7 \%$; en el Toro 2 entre 5.3 a $36.4 \%$; en el Toro 3 entre 23.7 a $37.0 \%$; y en el Toro 4, entre 27.6 a 33.3\%. Palma (2001) obtuvo en dos estudios una variabilidad de 10 a $51 \%$ y de 10 a $57 \%$. Los toros evaluados en el presente estudio tenían 18 meses de edad, lo que podría haber influido en las res- 
puestas de fertilidad y en la producción de blastocistos, ya que la fertilidad se incrementa con la edad (Decuadro y Hansen, 2000).

En el Cuadro 2 se observa que los toros con mayor motilidad postdescongelación fueron los que tuvieron una ligera menor tasa de fertilidad in vitro. Lo que sucede es que estas diferencias en motilidad son corregidas por la centrifugación por gradientes de Percoll donde se separan los espermatozoides más débiles y los muertos, y solo quedan en el pellet los más aptos para la inseminación. Los valores de motilidad postcapacitación con Percoll fueron más homogéneos, con excepción del Toro 1. Estos resultados concuerdan con los resultados de fertilización y producción de embriones donde los mejores resultados corresponden a los toros 3 y 4 .

\section{Conclusiones}

? La fertilidad in vitro de los toros fue aceptable y sin diferencias entre ellos.

? No se encontró diferencias estadísticas entre toros en la proporción de blastocistos obtenidos con relación al número de ovocitos madurados.

? Los resultados de motilidad postdescongelación no tuvieron relación con la fertilidad in vitro y la producción de embriones, ya que la técnica de capacitación espermática separa los mejores espermatozoides de cada toro.

\section{Literatura Citada}

1. Alberio R. 2003. Nuevas tecnologías reproductivas. Aspectos biológicos y económicos. Argentina: INTA Balcarce. $13 \mathrm{p}$.

2. Arlotto T, Schwartz IL, First NL, Leibfried ML 1996. Aspects of follicle and oocyte stage that affect in vitro maturation and development of bovine oocytes. Theriogenology 45: 943-956.
3. Bastidas P, Fernández A, Troconiz I. 1999. Fertilización in vitro heteróloga en búfalos. Arch Latinoam Prod Anim 5(Supl 1): 415-416.

4. Decuadro H, Hansen G. 2000. Fertilidad de los toros de inseminación artificial: Algunos factores de variación. IMV Technologies France. Centre d'Insémination artificieile de L' Aigle, France.

5. Galli C. 2003. Bovine embryo technologies. Theriogenology 59:599-616.

6. Lorenzo PL. 1994. Fecundación y desarrollos embrionario temprano. En: Reproducción de los animales domésticos. Cap. 6. Madrid: Ed. Aedos. p 182-187.

7. Madrid N. 2003. Relación entre los métodos de valoración seminal in vitro y la fertilidad in vivo del semen descongelado de toros frisones. Tesis Doctoral. Madrid: Facultad de Medicina Veterinaria, Univ. Complutense de Madrid.

8. Olivera M. 2003. Producción de embriones F1 BON para la caracterización de doble propósito y como apoyo a la cadena láctea y cárnica. Rev Col Cienc Pec 16(1): 78-82.

9. Palma G. 2001. Producción in vitro de embriones bovinos. En: Palma G. Biotecnología de la reproducción. Balcarce, Argentina: Ed. Reprobiotec. $\mathrm{p}$ 257-259.

10. Ramírez O, Jiménez C. 2003. Recolección de ovocitos para procedimientos in vitro en bovinos. Acovez 24(1): 4-9.

11. Ratto M, Berland M, Wolter M, Matamoros R. 1999. Desarrollo de embriones de bovino obtenidos por fecundación in vitro cultivados con células oviductuales o medio condicionado y transferidos a hembras receptoras. Arch Med Vet 31(1): 89-96.

12. Rei M, Ratto M, Silva M, Berland M. 2006. Desarrollo embrionario in vitro de ovocitos bovinos fecundados con espermatozoides adheridos al cumulus. Int J Morphol 24(Suppl 1): 125-132.

13. Salgado R, Rugeles C, ÁlvarezJ. 2005. Efecto de la heparina y de la concentración espermática sobre el porcentaje de fertilización de ovocitos bovinos in vitro. Rev Col Cienc Pec: 18(2): 122-126. 